\title{
UF FLOSIDA
}

\section{Exotic Diseases of Citrus}
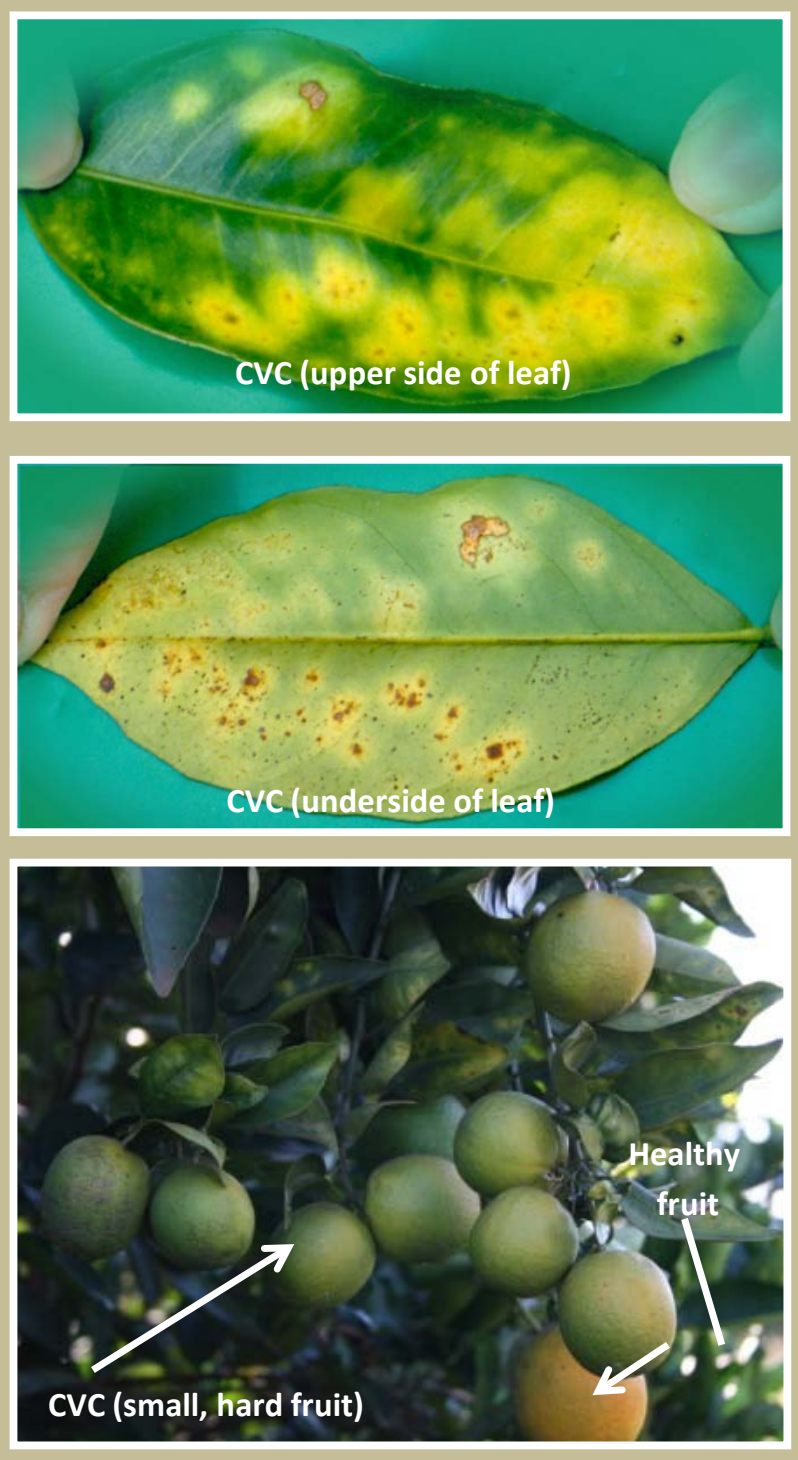

The Institute of Food and Agricultural Sciences (IFAS) is an Equal Employment Opportunity Institution authorized to provide research, educational information and other services only to individuals and institutions that function with nondiscrimination with respect to race, creed, color, religion, age, disability, sexual orientation, marital status, national origin, political opinions or affiliations. U.S. Department of Agriculture, Cooperative Extension Service, University of Florida, IFAS, Florida A. \& M. University Cooperative Extension Program, and Boards of Commissioners Cooperating. Millie Ferrer, Interim Dean
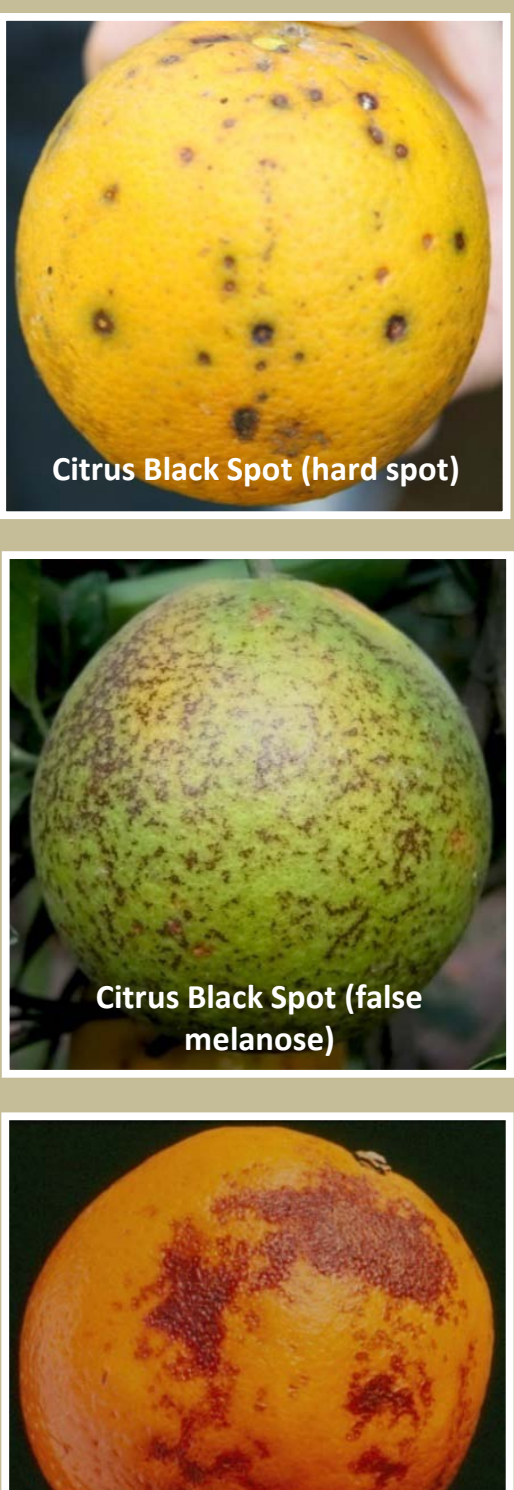

Citrus Black Spot (virulent spot)
Citrus Black Spot (hard spot)
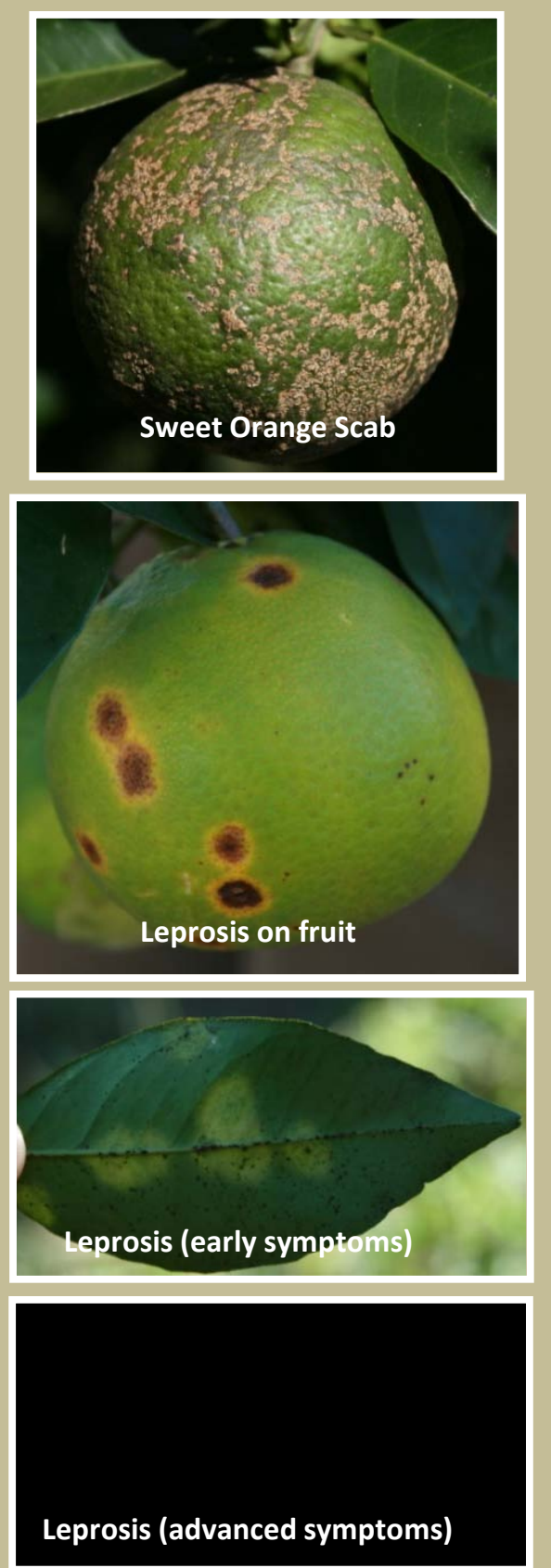

For more information, contact the University of Florida, IFAS, Citrus Research and Education Center 863-9561151, www.crec.ifas.ufl.edu, or your local county citrus extension agent

Photo Credit: J.D. Yates, M.M. Dewdney, M.E. Rogers, N.A. Peres, L.W. Tim. Dew, HJ, Korf
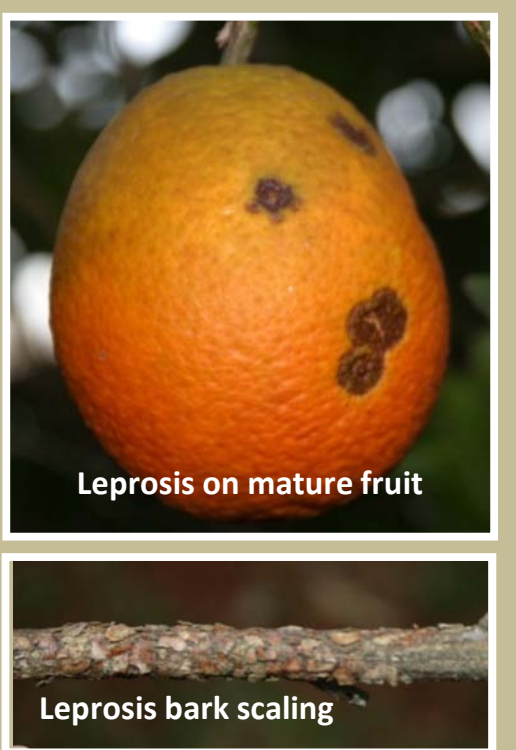

Leprosis bark scaling

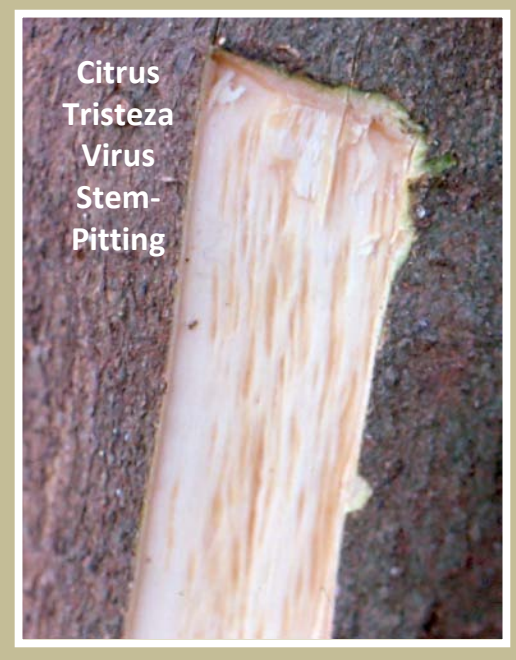

1. This document is PP264, one of a series of the Department of Plant Pathology, Florida Cooperative Extension Service, Institute of Food and Agricultural Sciences, University of Florida. First published: April 2009.

2. Megan M. Dewdney, assistant professor, Department of Plant Pathology, Jamie D. Yates, assistant coordinator for canker and greening extension 2. Megan M. Dewdney, assistant professor, Department of Plant Pathology, Jamie D. Yates, assistant coordinator for canker and greening extension
education, Michael E. Rogers, assistant professor, Department of Entomology, Timothy M. Spann, assistant professor, Department of Horticulture, Citrus REC, Lake Alfred, Florida; Cooperative Extension Service, Institute of Food and Agricultural Sciences; University of Florida; Gainesville, FL 32611. 


\begin{tabular}{|c|c|c|c|c|c|}
\hline & $\begin{array}{c}\text { CITRUS VARIEGATED } \\
\text { CHLOROSIS (CVC) }\end{array}$ & LEPROSIS & $\begin{array}{c}\text { CITRUS } \\
\text { BLACK SPOT }\end{array}$ & $\begin{array}{l}\text { SWEET ORANGE } \\
\text { SCAB (SOS) }\end{array}$ & $\begin{array}{c}\text { CITRUS TRISTEZA } \\
\text { STEM-PITTING } \\
\text { (CTV-SP) }\end{array}$ \\
\hline $\begin{array}{l}\text { Plant Tissue } \\
\text { Location }\end{array}$ & Xylem & $\begin{array}{l}\text { Cytoplasm or nucleus of } \\
\text { infected cells }\end{array}$ & Fruit rind and leaves & Fruit rind & Phloem \\
\hline Spread & $\begin{array}{c}\text { Sharpshooters, graft-transmitted, } \\
\text { seed (?) }\end{array}$ & $\begin{array}{l}\text { Several species of } \\
\text { Brevipalpus mites }\end{array}$ & $\begin{array}{l}\text { Warm wet conditions, } \\
\text { presence of susceptible } \\
\text { fruit, and presence of } \\
\text { abundant inoculum }\end{array}$ & $\begin{array}{c}\text { Requires moisture; } \\
\text { presence of susceptible } \\
\text { fruit; } \\
\text { splash by raindrops }\end{array}$ & $\begin{array}{l}\text { Several species of aphids } \\
\text { budding and grafting }\end{array}$ \\
\hline Pathogen & $\begin{array}{l}\text { Xylella fastidiosa } \\
\text { (Bacterium) }\end{array}$ & Citrus leprosis virus & $\begin{array}{c}\text { Guignardia citricarpa } \\
\text { (Fungus) }\end{array}$ & $\begin{array}{l}\text { Elsinoë australis } \\
\text { (Fungus) }\end{array}$ & Citrus tristeza virus \\
\hline Tree Symptoms & $\begin{array}{l}\text { Reduced vigor and growth; tree } \\
\text { not killed, but becomes } \\
\text { unproductive; symptoms may } \\
\text { appear in one branch or the } \\
\text { whole canopy }\end{array}$ & $\begin{array}{l}\text { Symptoms localized on fruit, } \\
\text { leaves, or twigs }\end{array}$ & $\begin{array}{l}\text { Extensive fruit drop if } \\
\text { severe }\end{array}$ & Unaffected & $\begin{array}{l}\text { Scattered pits after } \\
\text { removing bark from } \\
\text { affected plants; } \\
\text { depressed areas in the } \\
\text { bark }\end{array}$ \\
\hline Leaf Symptoms & $\begin{array}{l}\text { Severe chlorosis, reddish to } \\
\text { brown lesions on the lower side } \\
\text { corresponding to yellow areas on } \\
\text { the upper surface; may resemble } \\
\text { zinc deficiency in early stages }\end{array}$ & $\begin{array}{l}\text { Chlorotic at first then may } \\
\text { become brown with or } \\
\text { without a necrotic center; } \\
\text { smooth to touch }\end{array}$ & $\begin{array}{l}\text { Small, round sunken } \\
\text { necrotic spots with gray } \\
\text { centers (uncommon) }\end{array}$ & Unaffected & $\begin{array}{l}\text { Chlorosis and dieback } \\
\text { may occur }\end{array}$ \\
\hline $\begin{array}{l}\text { Stem/Twig } \\
\text { Symptoms }\end{array}$ & Unaffected & Bark scaling, twig dieback & As on leaves & Unaffected & $\begin{array}{l}\text { Twigs are brittle; bark is } \\
\text { abnormally thick; trunk } \\
\text { and branches may have a } \\
\text { ropy appearance }\end{array}$ \\
\hline Fruit Symptoms & $\begin{array}{l}\text { Small and hard with high acid; } \\
\text { fruit remains on the tree; may } \\
\text { exhibit sunburn damage; normal } \\
\text { color change }\end{array}$ & $\begin{array}{l}\text { Premature fruit drop, flat or } \\
\text { depressed lesions with } \\
\text { yellow halo; often with } \\
\text { brown centers }\end{array}$ & $\begin{array}{l}\text { Necrotic lesions; hard } \\
\text { spot, false melanose, and } \\
\text { virulent spot type } \\
\text { symptoms; does not cause } \\
\text { decay; if severe, may } \\
\text { cause extensive premature } \\
\text { fruit drop }\end{array}$ & $\begin{array}{l}\text { Young fruit have corky, } \\
\text { wart-like pustules; tan to } \\
\text { gray in color; mature } \\
\text { fruit lesions become } \\
\text { smoother }\end{array}$ & Small and misshapen \\
\hline Flowering & Off-season bloom & Unaffected & Unaffected & Unaffected & Off-season bloom \\
\hline Varieties Affected & Sweet orange & $\begin{array}{l}\text { Mainly sweet orange, } \\
\text { mandarins }\end{array}$ & $\begin{array}{l}\text { All citrus, except Tahiti } \\
\text { limes }\end{array}$ & $\begin{array}{l}\text { Sweet orange and } \\
\text { tangerines }\end{array}$ & $\begin{array}{l}\text { Lime, grapefruit, sweet } \\
\text { orange }\end{array}$ \\
\hline
\end{tabular}

